\title{
Presence of three mycorrhizal genes in the common ancestor of land plants suggests a key role of mycorrhizas in the colonization of land by plants
}

\author{
Bin Wang ${ }^{1}$, Li Huey Yeun ${ }^{2}$, Jia-Yu Xue ${ }^{1}$, Yang Liu ${ }^{1}$, Jean-Michel Ané ${ }^{2}$ and Yin-Long Qiu ${ }^{1}$ \\ ${ }^{1}$ Department of Ecology and Evolutionary Biology, University of Michigan, Ann Arbor, MI 48109, USA; ${ }^{2}$ Department of Agronomy, University of \\ Wisconsin, Madison, WI 53706, USA
}

\section{Summary}

Author for correspondence:

Yin-Long Qiu

Tel: +1 7347648279

Email:ylqiu@umich.edu

Received: 17 September 2009

Accepted: 18 November 2009

New Phytologist (2010) 186: 514-525

doi: 10.1111/j.1469-8137.2009.03137.x

Key words: $D M / 1, D M / 3$, embryophyte, evolution, IPD3, land plant, mycorrhiza, symbiosis.
- The colonization of land by plants fundamentally altered environmental conditions on earth. Plant-mycorrhizal fungus symbiosis likely played a key role in this process by assisting plants to absorb water and nutrients from soil.

- Here, in a diverse set of land plants, we investigated the evolutionary histories and functional conservation of three genes required for mycorrhiza formation in legumes and rice (Oryza sativa), DM/1, DMI3 and IPD3.

- The genes were isolated from nearly all major plant lineages. Phylogenetic analyses showed that they had been vertically inherited since the origin of land plants. Further, cross-species mutant rescue experiments demonstrated that $D M / 3$ genes from liverworts and hornworts could rescue Medicago truncatula dmi3 mutants for mycorrhiza formation. Yeast two-hybrid assays also showed that bryophyte DMI3 proteins could bind to downstream-acting M. trunculata IPD3 protein. Finally, molecular evolutionary analyses revealed that these genes were under purifying selection for maintenance of their ancestral functions in all mycorrhizal plant lineages.

- These results indicate that the mycorrhizal genes were present in the common ancestor of land plants, and that their functions were largely conserved during land plant evolution. The evidence presented here strongly suggests that plant-mycorrhizal fungus symbiosis was one of the key processes that contributed to the origin of land flora.

\section{Introduction}

Mycorrhizas, dual organs of absorption formed when symbiotic fungi inhabit healthy tissues of most plants (Trappe, 1996), are increasingly recognized to play roles in the cycling of phosphorus, nitrogen, and water in modern terrestrial ecosystems as well as enhancing plant tolerance to abiotic and biotic stresses (Harrison, 2005; Paszkowski, 2006; Parniske, 2008; Smith \& Read, 2008). They probably represent a key innovation that helped plants adapt to the harsh terrestrial environment during their initial colonization of land (Pirozynski \& Malloch, 1975; Selosse \& Le Tacon, 1998; Read et al., 2000; Kottke \& Nebel, 2005; Wang \& Qiu, 2006; Bonfante \& Genre, 2008), as water and nutrient shortages were some of the first challenges plants faced on land (Graham, 1993; Kenrick \& Crane,
1997; Gensel \& Edwards, 2001). Two lines of evidence have been presented to support this 'mycorrhizal landing' hypothesis. One is the occurrence of mycorrhizas in all major lineages of extant land plants except most mosses (Pirozynski \& Malloch, 1975; Harley \& Harley, 1987; Trappe, 1987; Boullard, 1988; Read et al., 2000; Brundrett, 2002; Wang \& Qiu, 2006; Smith \& Read, 2008). The other includes the fossils of glomalean fungi excavated from the Ordovician (Redecker et al., 2000); this group of fungi form arbuscular mycorrhizas with most extant land plants (Pirozynski \& Malloch, 1975; Read et al., 2000; Wang \& Qiu, 2006). This fossil evidence places the mycorrhizaforming fungi at the same age as the earliest land plants (Strother et al., 1996; Wellman et al., 2003).

However, three problems may undermine the 'mycorrhizal landing' hypothesis. First, the organs formed between 
plant and fungal partners in bryophytes and vascular plants are structurally nonhomologous but functionally analogous. In bryophytes the organs are parts of the haploid gametophyte on the plant (mycorhizoids or mycothalli), whereas in vascular plants they are parts of the diploid sporophyte (Brundrett, 2002; Wang \& Qiu, 2006; Ligrone et al., 2007; Bonfante \& Genre, 2008). Secondly, despite the report of glomalean fungi from the Ordovician (Redecker et al., 2000), mycorrhizas have not been directly observed in any of the plant fossils from that geological period (Strother et al., 1996; Wellman et al., 2003). The oldest mycorrhizal fossils, found in the underground rhizomes of prevascular plants excavated from the 400-million-yr-old Rhynie Chert of the Early Devonian in Scotland (Remy et al., 1994), are significantly younger than fossils of the earliest land plants (Strother et al., 1996; Wellman et al., 2003). Finally, host shifting by fungi from vascular plants to liverworts has been detected in two recent studies (Russell \& Bulman, 2005; Ligrone et al., 2007). This observation has led some to raise the possibility of an alternative 'hostshifting' hypothesis, which postulates that mycorrhizas originated in the common ancestor of vascular plants, and that the presence of these absorption organs in bryophytes was a result of host shifting by fungal symbionts (Selosse, 2005; Ligrone et al., 2007).

To test these hypotheses, we investigated the origin of the genetic machinery that allows plants to engage in symbiotic associations with mycorrhizal fungi. Logically, we focused our effort on the early-diverging lineages of land plants the paraphyletic bryophytes. Recently, phylogenetic relationships among three bryophyte lineages (liverworts, mosses, and hornworts) and vascular plants have been resolved with several types of molecular data: nucleotide sequences of chloroplast (atpB (ATP synthase CF1 beta subunit), $r b c L$ (ribulose-1,5-bisphosphate carboxylase/oxygenase large subunit), small subunit (SSU) and large subunit (LSU) rRNA), mitochondrial (atp1 (ATPase subunit 1) and LSU rRNA), and nuclear (18S rRNA) genes from 192 taxa (Qiu et al., 2007), the presence/absence of 28 mitochondrial group II introns in 16 charophytes and land plants, nucleotide sequences of 67 chloroplast protein genes from 36 taxa (Qiu et al., 2006), and 40 chloroplast genomic structural characters in 18 taxa (Kelch et al., 2004). This well-reconstructed plant phylogeny can serve as a framework with which to investigate the evolutionary history of a gene by comparing the gene phylogeny with the organismal phylogeny. Progress on molecular genetic studies of mycorrhizal development has also made this study possible. Intensive investigation of the nodulation process in legumes over the last $10 \mathrm{yr}$ serendipitously revealed that the rhizobium-plant symbiosis actually evolved from the more ancient mycorrhizal fungus-plant symbiosis, and that the two systems shared many genes in the early stage of microbe-plant communication. Four such symbiotic genes have been identified from Medicago truncatula and seven from Lotus japonicus (Harrison, 2005; Paszkowski, 2006; Parniske, 2008). Two have been shown to be well conserved for mycorrhiza formation across angiosperms (Chen et al., 2008; Markmann et al., 2008). However, little is known about the genetic mechanism of mycorrhizal symbiosis or even the extent of distribution of these genes in early land plants.

We selected three symbiotic genes for study here because they showed sufficiently high degrees of sequence conservation across the land plants in which they have been investigated. These genes encode proteins that are components of a well-coordinated signal transduction cascade (Parniske, 2008). DMI1 (Doesn't Make Infections 1), also known as POLLUX and CASTOR for the two copies in angiosperms, encodes a cation channel located on the nuclear envelope (Ané et al., 2004; Riely et al., 2007). DMI3 encodes a calcium/calmodulin-dependent protein kinase (CCaMK) that translates nuclear calcium spiking into phosphorylation events (Lévy et al., 2004). The third gene, IPD3 (Interacting Protein of DMI3) (CYCLOPS), encodes a protein that interacts with and is phosphorylated by the DMI3 (Doesn't Make Infections 3) protein in plant nuclei (Messinese et al., 2007; Yano et al., 2008). Mutagenesis and knockout experiments in M. truncatula, L. japonicus and Oryza sativa have confirmed the requirement of all three genes for arbuscular mycorrhiza formation, and in particular the dmi3 mutant has a strict nonmycorrhizal (Myc-) phenotype (Morandi et al., 2005; Chen et al., 2008).

\section{Materials and Methods}

DNA and RNA isolation, reverse transcriptase-polymerase chain reaction (RT-PCR) and rapid amplification of cDNA ends (RACE)

The thalli, roots or leaves were collected fresh from the field or from botanical gardens. Detailed information on the provenance of the plant material is included with voucher specimens, which are deposited in the various herbaria listed in Table 1. Total cellular DNAs were extracted with a modified CTAB (hexadecyltrimethylammonium bromide) method (Doyle \& Doyle, 1987) or the DNeasy Plant Mini kit (Qiagen). Total cellular RNA was extracted with the RNeasy Plant Mini kit (Qiagen).

To amplify homologs of the gene from diverse land plants, we used the COnsensus-Degenerate Hybrid Oligonucleotide Primer (CODEHOP) (Rose et al., 2003) primer-designing strategy. The target gene fragments were amplified from genomic DNA by PCR, and the products were cloned using the TOPO TA cloning kit (Invitrogen) and sequenced.

The first-strand cDNA was synthesized from $5 \mu \mathrm{g}$ of RNA with Superscript III reverse transcriptase (Invitrogen) 
Table 1 Sequences of the three genes obtained or used in the study ${ }^{1}$

\begin{tabular}{|c|c|c|c|c|}
\hline Species & $\begin{array}{l}\text { Doesn't Make } \\
\text { Infections } 1 \text { (DM/1) }\end{array}$ & $\begin{array}{l}\text { Doesn't Make } \\
\text { Infections } 3(D M / 3)\end{array}$ & $\begin{array}{l}\text { Interacting Protein } \\
\text { of DMI3 (IPD3) }\end{array}$ & $\begin{array}{l}\text { Voucher\# } \\
\text { (Herbarium) }\end{array}$ \\
\hline \multicolumn{5}{|l|}{ Liverworts } \\
\hline Haplomitrium gibbsiae & FJ913205 & FJ913229 & FJ913199 & Engel \& von Konrat $28341(\mathrm{~F})$ \\
\hline Treubia lacunosa & FJ913206 & FJ913230 & FJ913200 & Engel \& von Konrat $28345(F)$ \\
\hline Dumortiera hirsuta & FJ913208 & FJ913231 & FJ913191 & Qiu 06048 (MICH) \\
\hline Lunularia cruciata & & FJ913233 (FJ913254)* & & Qiu 01036 (MICH) \\
\hline Concephalum sp. & & FJ913234 (FJ913255)* & & Qiu 94096 (IND) \\
\hline Pellia epiphylla & FJ913207 & FJ913232 & FJ913196 & QW06018 (MICH) \\
\hline Trichocolea tomentella & FJ913209 & & FJ913192 & Qiu 06038 (MICH) \\
\hline \multicolumn{5}{|l|}{ Mosses } \\
\hline Takakia lepidozioides & FJ913210 (FJ913225) & FJ913235 (FJ913256) & & X-D Li $010(\mathrm{MICH})$ \\
\hline Polytrichum juniperinum & FJ913211 & FJ913236 & & QW06012 (MICH) \\
\hline Physcomitrella patens & $\begin{array}{l}\text { XM_001755593 } \\
\text { XM_001758311 }\end{array}$ & AY155462 & DS545208 & \\
\hline Fissidens taxifolius & & FJ913239 & FJ913198 & QW06020 (MICH) \\
\hline Mnium affine & & FJ913237 & & QW06014 (MICH) \\
\hline Climacium dendroides & FJ913212 & FJ913238 & FJ913197 & QW06019 (MICH) \\
\hline \multicolumn{5}{|l|}{ Hornworts } \\
\hline Anthoceros agrestis & FJ913213 (FJ913226) & & & Qiu $99112(Z)$ \\
\hline Phaeoceros laevis & FJ913215 & FJ913240 & & Qiu 06032 (MICH) \\
\hline Megaceros aenigmaticus & FJ913214 & FJ913241 & FJ913204 & Qiu 06044 (MICH) \\
\hline \multicolumn{5}{|l|}{ Lycophytes } \\
\hline Lycopodium digitatum & FJ913216 & FJ913242 & FJ913194 & Qiu 08001 (MICH) \\
\hline Huperzia squarrosa & FJ913217 & & FJ913195 & Qiu 05001 (MICH) \\
\hline Selaginella moellendorffii & $\begin{array}{l}\text { gnllNov06_ } \\
\text { contig|32.28 } \\
\text { gnllNov06_ } \\
\text { contig|187.13 }\end{array}$ & $\begin{array}{l}\text { gnllFeb06_ } \\
\text { Contig|101.15 }\end{array}$ & $\begin{array}{l}\text { gnllFeb06_ } \\
\text { Contig|8.14 }\end{array}$ & \\
\hline \multicolumn{5}{|l|}{ Monilophytes } \\
\hline Botrychium dissectum & & FJ913244 & & Qiu 96214 (IND) \\
\hline Osmunda regalis & & FJ913243 & & Qiu 02072 (MASS) \\
\hline \multicolumn{5}{|l|}{ Gymnosperms } \\
\hline Cycas revoluta & FJ913218 & FJ913245 & FJ913202 & Qiu 94051(IND) \\
\hline Zamia sp. & & & FJ913203 & Qiu 09001 (MICH) \\
\hline Ginkgo biloba & & FJ913246 & & Qiu 01001 (MASS) \\
\hline \multicolumn{5}{|l|}{ Angiosperms } \\
\hline Amborella trichopoda & & FJ913247 (FJ913257) & & Qiu 97123(IND) \\
\hline Peltandra virginica & FJ913223 (no DM/1b) & & & Qiu 08006 (MICH) \\
\hline Lilium longiflorum & & U24188* & & \\
\hline Smilacina racemosa & FJ913219 (no DM/1b) & FJ913248 & & QW06007 (MICH) \\
\hline Oryza sativa & $\begin{array}{l}\text { NM_001051466 } \\
\text { NM_001058400 }\end{array}$ & AC097175.2 & EF569223 & \\
\hline Zea mays & DQ403198, DQ403197 & DQ403196 & & \\
\hline Aquilegia formosa & $\begin{array}{l}\text { DT727692+ } \\
\text { DT727691, } \\
\text { DR940038+ } \\
\text { DT940037 }\end{array}$ & & & \\
\hline Clematis virginiana & FJ913221 (no DM/1b) & & & Povilus 08002 (MICH) \\
\hline Vitis vinifera & AM423798, CAO46310 & CU459288 & CU459357 & \\
\hline Arabidopsis thaliana & NM_124375 (no DM/1b) & & & \\
\hline Acer sp. & & FJ913250 & & QW06005 (MICH) \\
\hline Brassica chinensis & FJ913220 (FJ913227)* & & & Qiu 94122 (IND) \\
\hline Populus trichocarpa & $\begin{array}{l}\text { e_gw1.86.49.1 } \\
\text { e_gw1.XIX.2465.1 }\end{array}$ & LG_X|20438946|20441174 & LG_III000810 & \\
\hline Euphorbia milii & & FJ913249 (FJ913258)* & & Qiu 94056 (IND) \\
\hline Cucurbita pepo & FJ913224* & & & Qiu 08009 (MICH) \\
\hline Malus domestica & & Z38126* & & \\
\hline Ricinus communis & EEF35956, EEF44668 & & & \\
\hline Arachis hypogaea & & EU395429* & & \\
\hline Cercis canadensis & FJ913222 (FJ913228)* & FJ913251 (FJ913259)* & & Qiu 94127 (IND) \\
\hline
\end{tabular}


New

Phytologist

Table 1 (Continued)

\begin{tabular}{|c|c|c|c|c|}
\hline Species & $\begin{array}{l}\text { Doesn't Make } \\
\text { Infections } 1(D M / 1)\end{array}$ & $\begin{array}{l}\text { Doesn't Make } \\
\text { Infections } 3(D M / 3)\end{array}$ & $\begin{array}{l}\text { Interacting Protein } \\
\text { of DMI3 (IPD3) }\end{array}$ & $\begin{array}{l}\text { Voucher\# } \\
\text { (Herbarium) }\end{array}$ \\
\hline Lotus japonicus & $\begin{array}{l}\text { AB162158, } \\
\text { AB162157 }\end{array}$ & AM230792 & EF569221 & \\
\hline Medicago truncatula & $\begin{array}{l}\text { AY497771, } \\
\text { FJ974130 }\end{array}$ & AY502066 & EF117279 & \\
\hline Pisum sativum & AJ973194 (no DM/1b) & AY502067 & EF569222 & \\
\hline Sesbania rostrata & & EU622875* & & \\
\hline Lamium sp. & & FJ913252 (FJ913260)* & & Qiu 95019 (IND) \\
\hline Coffea arabica & & FJ913253 (FJ913261) & & Qiu 96113 (IND) \\
\hline Nicotiana tabacum & EF613118 & U70923*, U38446* & & \\
\hline Petunia $\times$ hybrida & (no $D M / 1 b)$ & EF592572 & & \\
\hline
\end{tabular}

${ }^{1}$ All sequences were used in the combined three-gene analyses except those with an asterisk, which were used only in single-gene analyses. The accessions in parentheses contain intron/exon information. The sequences obtained from GenBank are shown in gray.

in a volume of $20 \mu \mathrm{l}$ with oligo-dT primers. With the firststrand cDNA as a template, the target gene fragments were amplified, and then cloned and sequenced as described above.

To obtain the full-length coding sequence of a gene, we used the RACE method. RNA was treated as suggested in the protocol of the GeneRacer kit (Invitrogen) and reversetranscribed into first-strand cDNA. With the synthesized cDNA as a template, both $5^{\prime}$ - and $3^{\prime}$ - cDNA ends of the gene were amplified, cloned, and sequenced.

\section{Phylogenetic and molecular evolutionary analyses}

All sequences were aligned at both nucleotide and amino acid levels with ClustalX (Thompson et al., 1997) and Mega 4 (Tamura et al., 2007). Further alignment optimization was carried out manually in MCCLADE (Maddison \& Maddison, 2000). A maximum likelihood method of phylogenic analysis using the GTR + I + G model as implemented in RAxML (Stamatakis, 2006) was used to search for the most likely tree and a bootstrap analysis of 100 replicates was also conducted. The analysis was performed at the CIPRES portal (http://www.phylo.org/portal2/). Liverwort sequences were designated as the outgroup as all three genes were absent in the sequenced green algal genomes of Chlamydomonas reinhardtii, Ostreococcus lucimarinus and Ostreococcus tauri.

To detect modes of selection acting on a gene, a branchsite analysis (Zhang et al., 2005) was performed to calculate the ratio $(\omega)$ of the nonsynonymous nucleotide substitution rate $\left(d_{\mathrm{N}}\right)$ to the synonymous substitution rate $\left(d_{S}\right)$ using PAML (Yang, 2000). Because the topologies of the DMI1 and IPD3 gene trees (Supporting Information Figs S1, S3) differed slightly from the land plant phylogeny (Kelch et al., 2004; Qiu et al., 2006, 2007), these two trees were constrained according to the land plant phylogeny so that accurate divergence levels could be estimated. For DMI3, the topology obtained in the single-gene analysis (Fig. S2) was used. As mosses, with the exception of Takakia, lack mycorrhizas (Boullard, 1988; Read et al., 2000; Wang \& Qiu, 2006), and the branch from the ancestor shared by Takakia and other mosses to other mosses was exceptionally long, that branch was designated as the foreground whereas the rest of the tree was defined as the background. This analytical strategy was chosen to evaluate whether there was positive selection in that part of the tree and purifying selection in the rest of the tree.

\section{Cross-species mutant rescue experiment and yeast two-hybrid assay}

Six bryophytes were selected for cross-species rescue of an M. truncatula dmi3 mutant: Dumortiera hirsuta, Haplomitrium gibbsiae, Megaceros aenigmaticus, Polytrichum juniperinum, Phaeoceros laevis and Treubia lacunosa. All these bryophytes except $P$. juniperinum are mycorrhizal in natural conditions (Wang \& Qiu, 2006). For each bryophyte $D M I 3$, the full-length cDNA was first cloned into the $\mathrm{pENTR} / \mathrm{D}$ vector (Invitrogen), and then transferred into the pK7FWG2-RR binary vector via LR recombination (Invitrogen) to obtain 35S::bryophyte DMI3 fusion. The vector pK7FWG2-RR was created by cloning the AatIIHindIII fragment containing the GFP marker under the control of the $35 \mathrm{~S}$ cauliflower mosaic virus (CaMV) promoter from the Gateway vector pK7FWG2 (Karimi et al., 2002) into a modified Gateway vector, pK7GWIWG2(II)-Q10::DsRED (Limpens et al., 2005). The resulting plasmid DNA was then transformed into Agrobacterium rhizogenes MSU440 by electroporation. The A. rhizogenes transformants were further cultured on selective media at $30^{\circ} \mathrm{C}$ for $48 \mathrm{~h}$ before use.

Seeds of the M. truncatula dmi3 mutant (TRV25) were surface-sterilized, synchronized at $4^{\circ} \mathrm{C}$ for $48 \mathrm{~h}$ and germinated by incubation at room temperature overnight. Seedlings of $M$. truncatula TRV25 were transformed by cutting off root tips $(3 \mathrm{~mm})$ and then touching the transformed A. rhizogenes cells for $5 \mathrm{~s}$ with the wounded tips (Boisson- 
Dernier et al., 2001). For each $A$. rhizogenes transformant with a bryophyte gene, 40 seedlings were transformed. All treated seedlings were placed on sterile plates containing Farhaeus medium (Catoira et al., 2000) and incubated in a growth chamber $\left(25^{\circ} \mathrm{C} ; 16 \mathrm{~h}\right.$ day length). After $2 \mathrm{wk}$, all plants were checked under a fluorescent microscope for red fluorescence (DsRED1), which indicates successful transformation.

Transformed plants were then inoculated with a mycorrhizal fungus, Glomus intraradices (IRBV'95; Premier Tech Biotechnologies, Rivière-du-Loup, QC, Canada), either under nonsterile conditions (plants were transferred into pots containing sand and Turface ${ }^{\circledR}$ MVP (Profile Products LLC, Buffalo Grove, IL, USA)) or under sterile conditions (plants were kept inside on sterile plates). In both cases, 100 fungal spores were placed in the root area of each plant. The wild-type $M$. truncatula plants (Jemalong A17) were inoculated with $G$. intraradices as a positive control. Nontransformed dmi3 mutant plants (TRV25) were inoculated as a negative control. After $6-8 \mathrm{wk}$, roots were collected for staining. They were cleared in $10 \% \mathrm{KOH}$ at $90^{\circ} \mathrm{C}$ for $10 \mathrm{~min}$, acidified in $1 \% \mathrm{HCl}$ for $5 \mathrm{~min}$, and stained with
0.05\% Trypan Blue for $10 \mathrm{~min}$. The stained roots were checked under a light microscope for mycorrhizal infection.

Four bryophytes were included in the yeast two-hybrid assay: $H$. gibbsiae, $M$. aenigmaticus, $P$. juniperinum and $P$. laevis. Their full-length DMI3 cDNAs were inserted into the vector pBD-Gal4 (Stratagene, La Jolla, California, USA) in a correct reading frame with the DNA-binding motif of the yeast Gal4 protein (Gal4 is a transcription regulator that binds to a UAS (Upstream Activation Sequence) and activates the transcription of reporter genes in yeast two-hybrid). Similarly, a full-length $M$. truncatula IPD3 cDNA was inserted into the vector pAD-Gal4. The yeast strain AH109 was sequentially transformed with the fused pBD-Gal4 and pAD-Gal4 plasmids. The M. truncatula $D M I 3$ cDNA was cloned into the pBD-Gal4 vector and used as a positive control, whereas the empty pBD-Gal4 and $\mathrm{pAD}-\mathrm{Gal} 4$ vectors were used as negative controls as described previously (Messinese et al., 2007).

All transformed yeast cells were serial-diluted to obtain different concentrations. For each concentration, $4 \mu \mathrm{l}$ of cells was plated on each of three selection media: LW, lacking leucine and tryptophan $\left(\mathrm{Leu}^{-}, \mathrm{Trp}^{-}\right)$; $\mathrm{LWH}$, lacking

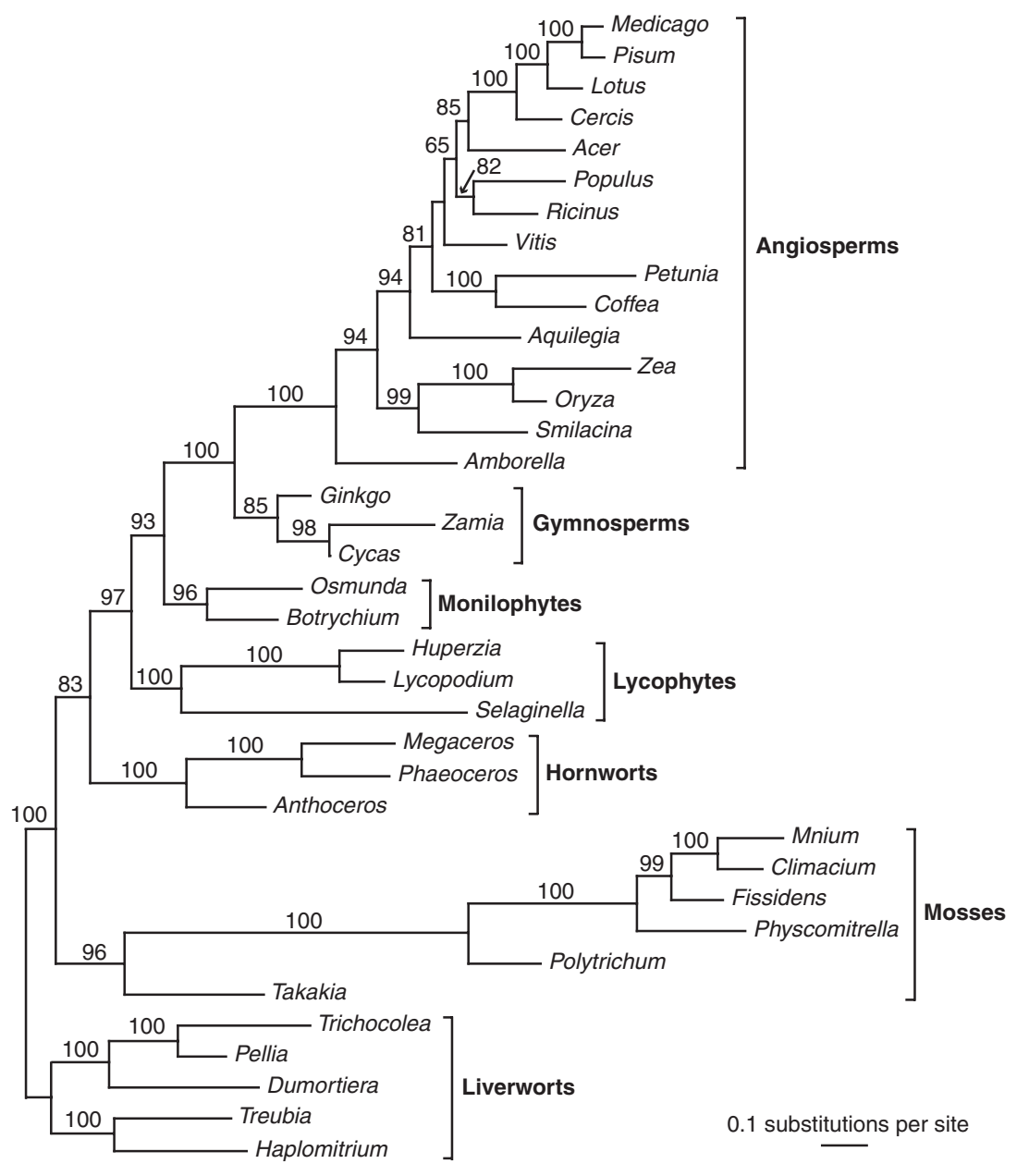

Fig. 1 A maximum likelihood tree obtained from analysis of the combined matrix of three mycorrhizal genes (Doesn't Make Infections 1 (DM/1), Doesn't Make Infections 3 (DM/3) and Interacting Protein of DMI3 (IPD3) of 37 land plants. The numbers above the branches are maximum likelihood bootstrap values. The branch length is proportional to the inferred divergence level. For DM/1, DM/1-1 from Physcomitrella patens, DM/1-x from Selaginella moellendorffii and DM/1b from the angiosperms were used to represent the gene in those species. 
New

leucine, tryptophan, and histidine ( $\left.\mathrm{Leu}^{-}, \mathrm{Trp}^{-}, \mathrm{His}^{-}\right)$; and LWHA, lacking leucine, tryptophan, histidine, and adenine $\left(\mathrm{Leu}^{-}, \mathrm{Trp}^{-}, \mathrm{His}^{-}, \mathrm{Ade}^{-}\right)$. All yeast cells on selection media were cultured at $30^{\circ} \mathrm{C}$ for $2 \mathrm{~d}$ before the results were checked.

\section{Results}

Sequences of the three genes were obtained from most of the diverse land plant species targeted (Table 1). Phylogenetic analyses using a maximum likelihood method (Stamatakis, 2006) of these sequences and some from GenBank showed that the three single-gene phylogenies (Figs S1-S3) are generally congruent with the land plant phylogeny reconstructed with both multigene supermatrices and phylogenomic data (Kelch et al., 2004; Qiu et al., 2006, 2007). A combined analysis of the three genes produced a phylogeny
(Fig. 1, Fig. S4) in complete agreement with the land plant phylogeny. Moreover, virtually all nodes in the three-gene phylogeny are strongly supported, with bootstrap values $>90 \%$.

For $D M I 3$ and $I P D 3$, only a single copy was isolated from all the species that yielded sequences. These genes probably exist as single-copy genes in the genomes of most, if not all, land plants, as inferred from Southern blots in $M$. truncatula and BLAST searches of sequenced genomes of Physcomitrella patens, Selaginella moellendorffi, O. sativa, Vitis vinifera and Populus trichocarpa (Arabidopsis thaliana lacks mycorrhizas and has neither gene). For DMI1, however, two copies were found in P. patens, S. moellendorffi, and most angiosperms. Their placement in the gene tree suggests that they were derived from recent independent duplications in Physcomitrella, lycophytes and angiosperms (Fig. S1). Despite these duplications, the reconstructed
Fig. 2 Recovery of mycorrhizal phenotypes after Medicago truncatula dmi3 mutant plants were transformed with Doesn't Make Infections 3 (DM/3) genes from Treubia lacunosa (a-c), Haplomitrium gibbsiae (d) (both liverworts) and Phaeoceros laevis (e) (hornwort). (a) A root showing a spore (S) and hyphae $(\mathrm{H})$ of Glomus intraradices. $(\mathrm{b}$ d, e) A root showing vesicles (V) and hyphae (H). (c) Cortical cells of a root with arbuscules (Ab). All photographs show Trypan Blue staining except (b), where no staining was used.

gene phylogeny suggests that there is an orthologous copy of DMI1 in most nonflowering land plants.

To evaluate the functional conservation of the three genes, we carried out several analyses. First, DMI3 was selected for cross-species (bryophytes to Medicago) mutant rescue experiments and yeast two-hybrid assays, as the dmi3 mutant has a strict nonmycorrhizal (Myc-) phenotype (Morandi et al., 2005). These assays were chosen over knock-out experiments in bryophytes because the only welldeveloped bryophyte model organism, $P$. patens, is like most mosses in lacking mycorrhizas, and the liverwort Marchantia polymorpha, which is amenable to some genetic manipulation, has no nonmycorrhizal mutant isolated to date. In the cross-species mutant rescue experiment, full-length DMI3 sequences of several liverworts, mosses, and hornworts were expressed in $M$. truncatula dmi3 mutant plants under the control of a $35 \mathrm{~S}$ CaMV promoter, which allowed a complete rescue of $d m i 3$ mutants with the $M$. truncatula DMI3 gene. The DMI3 genes from $H$. gibbsiae and $T$. lacunosa (both liverworts) and $P$. laevis (hornwort) were able to rescue the $M$. truncatula mutant, producing vesicles and arbuscules (Fig. 2, Table S1). The DMI3 from P. laevis was even able to partially rescue the nodulation phenotype of the dmi3 mutant as a few infection threads (but no nodule primordium) were observed in the presence of compatible rhizobia. However, the gene from P. juniperinum (moss) failed to rescue the mutant. This result is consistent with the facts that most mosses lack mycorrhizas (Boullard, 1988; Read et al., 2000; Wang \& Qiu, 2006), that their DMI3 proteins failed to interact with the $M$. truncatula IPD3 protein in the yeast two-hybrid assay (Fig. 3), and that their genes show elevated evolutionary rates and may have diverged for new functions (Table 2). For transgenic plants trans-
Table 2 The results of the branch-site analyses for selection mode acting on the three mycorrhizal genes in the whole land plant tree excluding the moss branch, and the moss branch

\begin{tabular}{|c|c|c|c|}
\hline Gene & $\begin{array}{l}\omega \text {-value for the } \\
\text { whole tree } \\
\text { excluding the } \\
\text { moss branch }\end{array}$ & $\begin{array}{l}\omega \text {-value for the } \\
\text { moss branch }\end{array}$ & $P$-value \\
\hline $\begin{array}{l}\text { Doesn't Make } \\
\text { Infections } 1(D M / 1)\end{array}$ & 0.0545 & 1.8049 & 0.1561 \\
\hline $\begin{array}{l}\text { Doesn't Make } \\
\text { Infections } 3(D M / 3)\end{array}$ & 0.0745 & 2.1763 & $0.0504^{*}$ \\
\hline $\begin{array}{l}\text { Interacting Protein } \\
\text { of DMI3 (IPD3) }\end{array}$ & 0.1065 & 7.8571 & $0.0118 * *$ \\
\hline
\end{tabular}

Significance: * ${ }^{*}$ 95\% level; ${ }^{*}$, $99 \%$ level; $P$-values are for the test of positive selection acting on the moss branch.

formed with DMI3 genes from D. hirsuta (liverwort) and $M$. aenigmaticus (hornwort), no recovery of mycorrhizal phenotype was observed, probably because of the small number of transgenic plants generated or insufficient observations made in the study (Table S1). In the yeast two-hybrid assay, DMI3 proteins from $H$. gibbsiae, $M$. aenigmaticu and $P$. laevis could interact with the $M$. truncatula IPD3 protein as the $M$. truncatula DMI3 protein did (the positive control), whereas the DMI3 protein from $P$. juniperinum could not (Fig. 3).

Secondly, branch-site analyses (Zhang et al., 2005) were performed on the three genes to examine the selection mode using PAML (Yang, 2000). Purifying selection was detected for all three genes in much of the tree $(\omega$ value $<1)$, with the sole exception of the branch leading to non-Takakia mosses, where the genes were under positive selection $(\omega$ value $>1$ ), presumably as a result of functional divergence

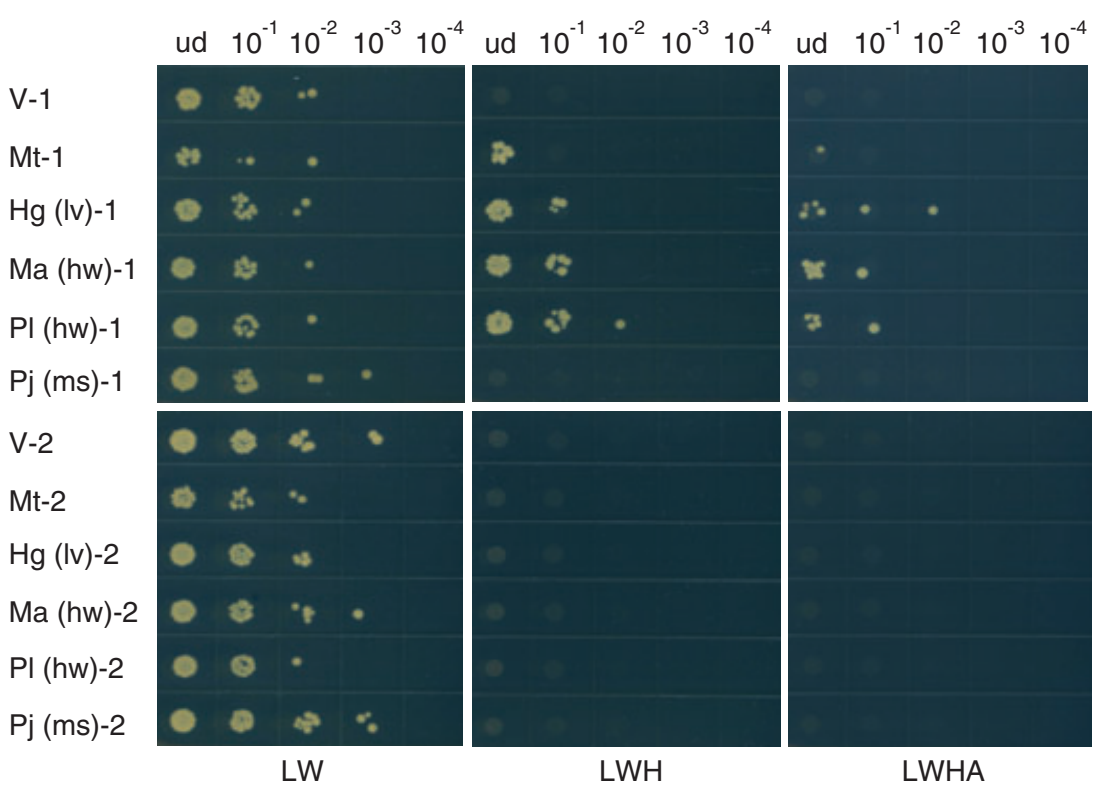

Fig. 3 The yeast two-hybrid assay results. Positive interactions occurred between liverwort (lv) (Haplomitrium gibbsiae, Hg)/hornwort (hw) (Megaceros aenigmaticus, Ma; Phaeoceros laevis, PI) Doesn't Make Infections 3 (DMI3) proteins and the Medicago truncatula (Mt) Interacting Protein of DMI3 (IPD3) protein (lanes Hg-1, Ma-1, and PI-1), but a negative interaction occurred between the moss (Polytrichum juniperinum, Pj) DMI3 protein and the $M$. truncatula IPD3 protein (lane Pj-1). Lane $\mathrm{V}-1$ (no insert in the bait vector $\mathrm{pBD}-\mathrm{Gal} 4$ ) and all six treatments in the bottom panel (no M. truncatula IPD3 insert in the prey vector $P A D-G a l 4$ ) were negative controls. Mt-1 was a positive control (M. truncatula DMI3 and IPD3 in the bait and prey vectors, respectively). Five concentrations of yeast cells were used (ud: undiluted). Selection media were: LW, $\mathrm{Leu}^{-} \mathrm{Trp}^{-}$; LWH, Leu ${ }^{-} \mathrm{Trp}^{-} \mathrm{His}^{-}$; LWHA, $\mathrm{Leu}^{-} \mathrm{Trp}^{-} \mathrm{His}^{-}$ Ade $^{-}$. 
New

(Table 2). Purifying selection generally allows maintenance of the ancestral function of a gene during evolution.

Finally, examination of the alignment of the amino acid sequences encoded by the three genes showed that various functional domains identified in the legume proteins (Ané et al., 2004; Lévy et al., 2004; Messinese et al., 2007) were well conserved. The following domains were especially highly conserved between bryophytes and angiosperms: the putative pore and the hinge region in the DMI1 protein, the calmodulin-binding (CaM) domain in the DMI3 protein, and the coiled-coil domain in the IPD3 protein (Fig. S5).

To determine the phylogenetic point at which these three genes originated, we performed BLAST searches in the fully sequenced nuclear genomes of three green algae, C. reinhardtii, $O$. lucimarinus and $O$. tauri. None of the three genes was present in the three genomes. Further BLAST searches of GenBank using conserved functional domains of
DMI1 and IPD3 did not detect any ancestral homolog. $D M I 3$, however, is known to be related to calcium-dependent protein kinase (CDPK) (Lévy et al., 2004). A comprehensive phylogenetic analysis including most CDPK sequences of land plants and green algae and all land plant $D M I 3$ sequences showed that the land plant CDPK and $D M I 3$ sequences formed two strongly supported clades (Fig. 4, Table S2). Not surprisingly, they were both placed among green algal $C D P K$ sequences. While the land plant $C D P K$ clade had a short branch, the land plant DMI3 clade had a rather long branch (the placement of the two lycophytes at the base of the DMI3 clade is probably an analytical artifact caused by the high degree of divergence between the two Chlamydomonas CDPK sequences and the DMI3 sequences). These results suggest that DMI3 originated through gene duplication from $C D P K$ during green alga evolution and probably also gained a new function after duplication. Because no sequence of either CDPK or DMI3 (a)

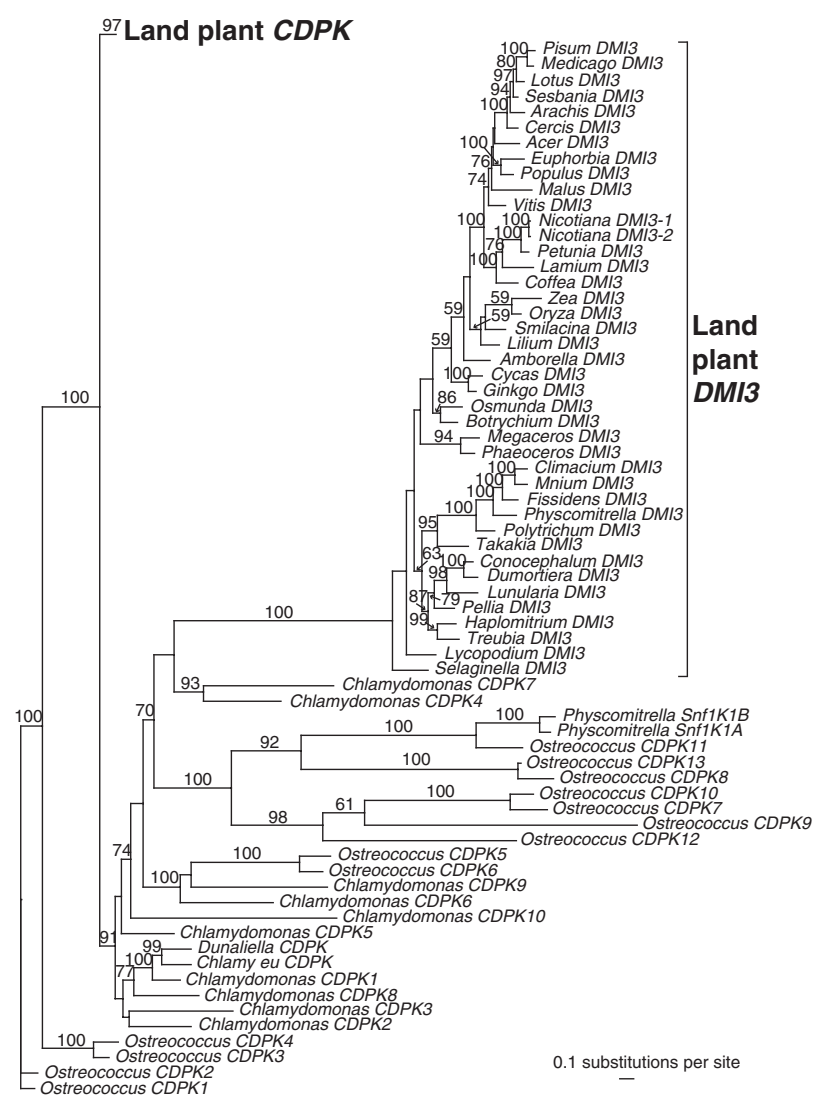

(b)

b) 0.1 substitutions per site

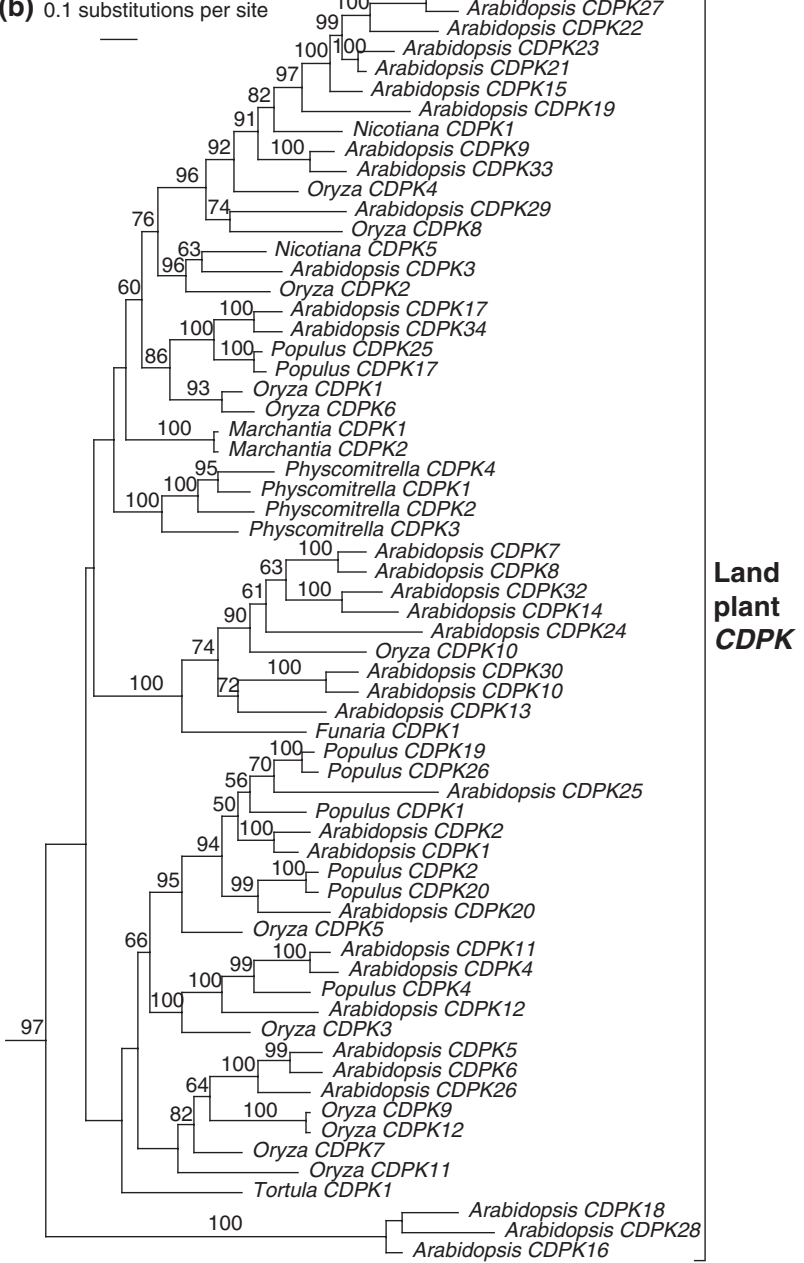

Fig. 4 A maximum likelihood tree derived from green alga and land plant calcium-dependent protein kinase (CDPK) sequences and Doesn't Make Infections 3 (DMI3) sequences (see Supporting Information Table S2 for sequence information). The numbers above the branches are maximum likelihood bootstrap values. The branch length is proportional to the inferred divergence level. 
was available from charophytic algae (our repeated efforts to amplify DMI3 from Chara contraria and Nitella mucronata yielded no product), determination of the precise phylogenetic point at which $D M I 3$ arose in green algae, if it did so, must await future studies. However, the results obtained here are consistent with the idea that the genetic machinery for mycorrhizal symbiosis originated during the colonization of land by plants.

\section{Discussion}

The results presented here allow two conclusions to be drawn. The first conclusion is that orthologous copies of the three mycorrhizal genes were present in the common ancestor of land plants, because they are present in nearly all major lineages of extant land plants, including liverworts the earliest-diverging lineage of land plants (Mishler \& Churchill, 1984; Qiu et al., 1998) - and that these genes have been vertically inherited during land plant evolution, as demonstrated by the highly congruent gene and plant phylogenies. The 'host-shifting' hypothesis (Selosse, 2005; Ligrone et al., 2007) requires evidence of horizontal gene transfer, and is thus not supported by the data obtained here. In the original version of the 'host-shifting' hypothesis, there was no elaborate molecular mechanism to explain how host-shifting might have happened. Given that both bryophytes and glomalean fungi were around in the Ordovician (Strother et al., 1996; Redecker et al., 2000; Wellman et al., 2003), one might ask why they did not form symbiotic associations then. One explanation could be that bryophytes did not have the genes and only acquired them later via horizontal transfer from vascular plants, which according to this hypothesis were the first plants with the capacity to form mycorrhizas. A 'reversion hypothesis' was also suggested, which postulates that the common ancestor of land plants had the capability to form mycorrhizas and transmitted it to one lineage (the common ancestor of mosses and vascular plants), whereas other lineages (e.g. non-Takakia mosses and liverworts) lost that capability and then acquired it again (e.g. liverworts) (Selosse, 2005). This hypothesis similarly would require regaining of the mycorrhizal genes, which is not supported by the phylogenies of the three mycorrhizal genes reconstructed in this study (Figs S1-S3).

The second conclusion is that the functions of these three genes in controlling the plant-mycorrhizal fungus symbiosis have been largely conserved throughout land plants (with the exception of most mosses), as shown by the results of the cross-species mutant rescue experiments and the yeast two-hybrid assays for DMI3, detection of purifying selection acting on all three genes in most parts of the singlegene phylogenies, and the highly conserved functional domains of the three proteins. Lack of any ancient duplication that could be traced back to the beginning of land plant evolution also corroborates this finding, as gene duplication sometimes results in functional diversification (neofunctionalization), as in the case of hemoglobin genes involved in the plant-nitrogen-fixing bacteria symbiosis (Guldner et al., 2004). The consistency of all these results thus unambiguously established the evolutionary homology of symbiotic interactions between gametophytes of liverworts/hornworts and mycorrhizal fungi and those between sporophytes of vascular plants and the fungi.

Over the last $10 \mathrm{yr}$, morphologically highly similar structures to the arbuscles and vesicles typically seen in mycorrhizas of vascular plants have been found in the thalli or underground organs of diverse liverworts (Carafa et al., 2003; Russell \& Bulman, 2005; Duckett et al., 2006; Ligrone et al., 2007) and a hornwort (Schussler, 2000). More recently, a study has demonstrated phosphorus translocation from the fungi $G$. intraradices and Glomus proliferum to the host liverwort Lunularia cruciata (Fonseca \& Berbara, 2008). Given the general functions of mycorrhizas in assisting plants in the uptake of phosphorus, nitrogen, and water, and in enhancing the ability of plants to deal with environmental stresses (Harrison, 2005; Paszkowski, 2006; Parniske, 2008; Smith \& Read, 2008), and the barren environment encountered by early land plants (Graham, 1993; Kenrick \& Crane, 1997; Gensel \& Edwards, 2001), it is reasonable to deduce from the conclusions reached above that plant-mycorrhizal fungus symbiosis played an essential role in the colonization of land by plants.

One might wonder why the genetic machinery underlying the plant-mycorrhizal fungus symbiosis is so conserved across such a wide range of evolutionary divergence, and in particular why there is a lack of duplication for two of the three genes investigated here, as nuclear genes often experience duplications during major evolutionary events. The answer may lie in the fact that arbuscular mycorrhiza symbiosis occurs between c. 150 species of glomalean fungi (Morton \& Benny, 1990) and a vast majority of the 300000 species of land plants (Harley \& Harley, 1987; Trappe, 1987; Wang \& Qiu, 2006; Smith \& Read, 2008), and this is the most ancestral form among all mycorrhiza symbioses (Wang \& Qiu, 2006). The evolutionary space of the mycorrhizal genes may have been strictly dictated by the small number of glomalean fungal species, which obviously did not diversify much during more than 450 million yr of evolution (Redecker et al., 2000). Repeated formation of partnerships between ascomycetes or basidiomycetes and different plant groups to form other types of mycorrhizas and the much more recent evolution of the interaction between nitrogen-fixing bacteria and some rosid angiosperms were all built on this ancient symbiotic pathway. The genes controlling events downstream of the initial plant-microbe communication signal transduction cascade encoded by the genes studied here can be expected to be less conserved in these other symbiotic systems. The molecular 
mechanisms that enabled ascomycetes and basidiomycetes to replace glomalean fungi as symbiotic partners in those plant lineages that adapted to nutrient-poor or nutrient-fast cycling environments (Malloch et al., 1980; Selosse, 2005; Wang \& Qiu, 2006; Bidartondo \& Duckett, in press) should be of particular interest in future mycorrhiza evolutionary studies.

The origin of land plants was one of the major events in the history of life on earth (Graham, 1993; Kenrick \& Crane, 1997; Gensel \& Edwards, 2001; Qiu, 2008). The question of how this important evolutionary transition was completed has never been satisfactorily answered. Although it was suggested more than $30 \mathrm{yr}$ ago that plant-mycorrhizal fungus symbiosis might have played an important role in this process (Pirozynski \& Malloch, 1975), little progress was made until recently. A significant body of evidence has been gathered over the last $10 \mathrm{yr}$, which in total seems to paint a fairly consistent picture suggesting that mycorrhizas were intimately involved in the colonization of the land by green plants: the discovery of glomalean fungus and bryophyte fossils in the Ordovician (Strother et al., 1996; Redecker et al., 2000; Wellman et al., 2003), the observation of mycorrhizas in fossils of prevascular plants from the Early Devonian (Remy et al., 1994), the demonstration of mycorrhizal structures in thalli and rhizoids of liverworts and hornworts (Schussler, 2000; Carafa et al., 2003; Russell \& Bulman, 2005; Duckett et al., 2006; Ligrone et al., 2007) and nutrient flow through these structures between glomalean fungi and liverworts (Fonseca \& Berbara, 2008), and reports of the widespread occurrence of mycorrhizas throughout land plants, with the exception of most mosses (Harley \& Harley, 1987; Trappe, 1987; Boullard, 1988; Read et al., 2000; Brundrett, 2002; Wang \& Qiu, 2006; Smith \& Read, 2008). The molecular evolutionary and functional evidence obtained in this study should now clearly establish the role of mycorrhizas in the origin of land flora.

The results of this study have profound implications in plant biology, ecology, and evolutionary biology. The antiquity of the plant-fungus interaction suggested here, which can be estimated to be at least 480 million yr old given the age of the oldest land plant fossils uncovered to date (Strother et al., 1996), and the widespread distribution of mycorrhizas demonstrated elsewhere (Harley \& Harley, 1987; Trappe, 1987; Read et al., 2000; Wang \& Qiu, 2006) highlight the necessity of preserving both above- and underground biodiversity in environment conservation efforts. The long history of the plant-mycorrhizal fungus association as suggested here also indicates that there is great potential for the use of mycorrhizas in the development of sustainable agriculture ecosystems (Harrison, 2005; Paszkowski, 2006; Parniske, 2008; Smith $\&$ Read, 2008). Finally, the demonstration that fungi directly participated in the initial establishment of the extant terrestrial ecosystems, more precisely biosystems, which operated at an unprecedented level of matter, energy, and information flow (metabolism and reproduction), adds another example to the list of major events in the history of life that were made possible through symbiosis (e.g. the origin of eukaryotes) (Sagan (Margulis) (1967); Maynard Smith \& Szathmary, 1995), underscoring the role of symbiosis in the generation and maintenance of biodiversity on earth.

\section{Acknowledgements}

We thank G. C. Adams, M. Bakewell, S. Cho, H. Jin, J. Li, W. Qian, P. Shi, M. Venkateshwaran, A. J. Wiederhold, Z. Yan, D. R. Zak, and J. Zhang for technical help, Z. D. Chen, G. S. Du, J. Engle, Y-K. He, Y. Jia, M. von Konrat, X-D. Li, K. D. McFarland, D. K. Smith, and M-Z. Wang for plant material, and S. McDaniel, M-A. Selosse and three anonymous referees for their suggestions which led to significant improvement of the manuscript. This work was supported by grants from NSF to Y-L.Q. (DEB 0332298 and 0531689) and to the UW Madison Plant Imaging Center (DBI 0421266), and from USDA-CSREES to J.M.A. (05-562-35319).

\section{References}

Ané JM, Kiss GB, Riely BK, Penmetsa RV, Oldroyd GED, Ayax C, Levy J, Debelle F, Baek JM, Kalo P et al. 2004. Medicago truncatula dmi1 required for bacterial and fungal symbioses in legumes. Science 303 : 1364-1367.

Bidartondo MI, Duckett JG. (in press). Conservative ecological and evolutionary patterns in liverwort-fungal symbioses. Proceedings of the Royal Society of London, Series B, Biological Sciences.

Boisson-Dernier A, Chabaud M, Garcia F, Becard G, Rosenberg C, Barker DG. 2001. Agrobacterium rhizogenes-transformed roots of medicago truncatula for the study of nitrogen-fixing and endomycorrhizal symbiotic associations. Molecular Plant-Microbe Interactions 14: 695-700.

Bonfante P, Genre A. 2008. Plants and arbuscular mycorrhizal fungi: an evolutionary-developmental perspective. Trends in Plant Science 13: 492-498.

Boullard B. 1988. Observations on the coevolution of fungi and hepatics. In: Pirozynski KA, Hawksworth DL, eds. Coevolution of fungi with plants and animals. London, UK: Academic Press, 107-124.

Brundrett MC. 2002. Coevolution of roots and mycorrhizas of land plants. New Phytologist 154: 275-304.

Carafa A, Duckett JG, Ligrone R. 2003. Subterranean gametophytic axes in the primitive liverwort haplomitrium harbour a unique type of endophytic association with aseptate fungi. New Phytologist 160: 185-197.

Catoira R, Galera C, de Billy F, Penmetsa RV, Journet EP, Maillet F, Rosenberg C, Cook D, Gough C, Dénarié J. 2000. Four genes of medicago truncatula controlling components of a nod factor transduction pathway. Plant Cell 12: 1647-1666.

Chen CY, Ané JM, Zhu HY. 2008. Osipd3, an ortholog of the medicago truncatula dmi3 interacting protein ipd 3 , is required for mycorrhizal symbiosis in rice. New Phytologist 180: 311-315.

Doyle JJ, Doyle JS. 1987. A rapid DNA isolation procedure for small quantities of fresh leaf tissue. Phytochemical Bulletin 19: 11-15. 
Duckett JG, Carafa A, Ligrone R. 2006. A highly differentiated glomeromycotean association with the mucilage-secreting, primitive antipodean liverwort treubia (treubiaceae): clues to the origins of mycorrhizas. American Journal of Botany 93: 797-813.

Fonseca HMAC, Berbara RLL. 2008. Does lunularia cruciata form symbiotic relationships with either glomus proliferum or $g$. Intraradices? Mycological Research 112: 1063-1068.

Gensel PG, Edwards D, eds. 2001. Plants invade the land. New York, NY, USA: Columbia University Press.

Graham LE. 1993. Origin of land plants. New York, NY, USA: John Wiley $\&$ Sons, Inc.

Guldner E, Godelle B, Galtier N. 2004. Molecular adaptation in plant hemoglobin, a duplicated gene involved in plant-bacteria symbiosis. Journal of Molecular Evolution 59: 416-425.

Harley JL, Harley EL. 1987. A checklist of mycorrhiza in the british flora. New Phytologist 105: 1-102.

Harrison MJ. 2005. Signaling in the arbuscular mycorrhizal symbiosis. Annual Review of Microbiology 59: 19-42.

Karimi M, Inzé D, Depicker A. 2002. Gateway ${ }^{\mathrm{TM}}$ vectors for agrobacterium-mediated plant transformation. Trends in Plant Science 7: 193195.

Kelch DG, Driskell A, Mishler BD. 2004. Inferring phylogeny using genomic characters: a case study using land plant plastomes. In: Goffinet B, Hollowell V, Magill R, eds. Molecular systematics of bryophytes. St Louis, MO, USA: Missouri Botanical Garden Press, 3-11.

Kenrick P, Crane PR. 1997. The origin and early evolution of plants on land. Nature 389: 33-39.

Kottke I, Nebel M. 2005. The evolution of mycorrhiza-like associations in liverworts: an update. New Phytologist 167: 330-334.

Lévy J, Bres C, Geurts R, Chalhoub B, Kulikova O, Duc G, Journet EP, Ané JM, Lauber E, Bisseling T et al. 2004. A putative ca2+ and calmodulin-dependent protein kinase required for bacterial and fungal symbioses. Science 303: 1361-1364.

Ligrone R, Carafa A, Lumini E, Bianciotto V, Bonfante P, Duckett JG. 2007. Glomeromycotean associations in liverworts: a molecular, cellular, and taxonomic analysis. American Journal of Botany 94: 1756-1777.

Limpens E, Mirabella R, Fedorova E, Franken C, Franssen H, Bisseling T, Geurts R. 2005. Formation of organelle-like n2-fixing symbiosomes in legume root nodules is controlled by dmi2. Proceedings of the National Academy of Sciences, USA 102: 10375-10380.

Maddison D, Maddison W. 2000. Macclade 4: analysis of phylogeny and character evolution. Sunderland, MA, USA: Sinauer.

Malloch DW, Pirozynski KA, Raven PH. 1980. Ecological and evolutionary significance of mycorrhizal symbioses in vascular plants (a review). Proceedings of the National Academy of Sciences, USA 77: 2113-2118.

Markmann K, Giczey G, Parniske M. 2008. Functional adaptation of a plant receptor-kinase paved the way for the evolution of intracellular root symbioses with bacteria. PLoS Biology 6: 497-506.

Maynard Smith J, Szathmary E. 1995. The major transitions in evolution. Oxford, UK: Oxford University Press.

Messinese E, Mun J-H, Li H-Y, Jayaraman D, Rouge P, Barre A, Lougnon G, Schornack S, Bono J-J, Cook DR et al. 2007. A novel nuclear protein interacts with the symbiotic dmi3 ccamk in Medicago truncatula. Molecular Plant-Microbe Interactions 20: 912-921.

Mishler BD, Churchill SP. 1984. A cladistic approach to the phylogeny of the bryophytes. Brittonia 36: 406-424.

Morandi D, Prado E, Sagan M, Duc G. 2005. Characterisation of new symbiotic Medicago truncatula (gaertn.) mutants, and phenotypic or genotypic complementary information on previously described mutants. Mycorrhiza 15: 283-289.

Morton JB, Benny GL. 1990. Revised classification of arbuscular mycorrhizal fungi (zygomycetes): a new order, glomales, two new sub-orders, glomineae and gigasporineae, and two new families, acaulosporaceae and gigasporaceae, with emendation of glomaceae. Mycotaxon 37: 471-491.
Parniske M. 2008. Arbuscular mycorrhiza: the mother of plant root endosymbioses. Nature Reviews: Microbiology 6: 763-775.

Paszkowski U. 2006. A journey through signaling in arbuscular mycorrhizal symbioses. New Phytologist 172: 35-46.

Pirozynski KA, Malloch DW. 1975. Origin of land plants - matter of mycotrophism. BioSystems 6: 153-164.

Qiu Y-L. 2008. Phylogeny and evolution of charophytic algae and land plants. Journal of Systematics and Evolution 46: 287-306.

Qiu Y-L, Cho YR, Cox JC, Palmer JD. 1998. The gain of three mitochondrial introns identifies liverworts as the earliest land plants. Nature 394: 671-674.

Qiu Y-L, Li LB, Wang B, Chen ZD, Knoop V, Groth-Malonek M, Dombrovska O, Lee J, Kent L, Rest J et al. 2006. The deepest divergences in land plants inferred from phylogenomic evidence. Proceedings of the National Academy of Sciences, USA 103: 15511-15516.

Qiu Y-L, Li LB, Wang B, Chen ZD, Dombrovska O, Lee J, Kent L, Li RQ, Jobson RW, Hendry TA et al. 2007. A nonflowering land plant phylogeny inferred from nucleotide sequences of seven chloroplast, mitochondrial, and nuclear genes. International Journal of Plant Sciences 168: 691-708.

Read DJ, Duckett JG, Francis R, Ligrone R, Russell A. 2000. Symbiotic fungal associations in 'lower' land plants. Philosophical Transactions Of The Royal Society OfLondon Series B-Biological Sciences 355: 815-830.

Redecker D, Kodner R, Graham LE. 2000. Glomalean fungi from the ordovician. Science 289: 1920-1921.

Remy W, Taylor TN, Hass H, Kerp H. 1994. Four-hundred-millionyear-old vesicular-arbuscular mycorrhizae. Proceedings of the National Academy of Sciences, USA 91: 11841-11843.

Riely BK, Lougnon G, Ané JM, Cook DR. 2007. The symbiotic ion channel homolog dmi1 is localized in the nuclear membrane of Medicago truncatula roots. Plant Journal 49: 208-216.

Rose TM, Henikoff JG, Henikoff S. 2003. Codehop (consensus-degenerate hybrid oligonucleotide primer) pcr primer design. Nucleic Acids Research 31: 3763-3766.

Russell J, Bulman S. 2005. The liverwort Marchantia foliacea forms a specialized symbiosis with arbuscular mycorrhizal fungi in the genus glomus. New Phytologist 165: 567-579.

Sagan (Margulis) L. 1967. On the origin of mitosing cells. Journal of Theoretical Biology 14: 225-274.

Schussler A. 2000. Glomus claroideum forms an arbuscular mycorrhiza-like symbiosis with the hornwort Anthoceros punctatus. Mycorrhiza 10: 1521.

Selosse M-A. 2005. Are liverworts imitating mycorrhizas? New Phytologist 165: 345-349.

Selosse M-A, Le Tacon F. 1998. The land flora: a phototroph-fungus partnership? Trends in Ecology \& Evolution 13: 15-20.

Smith SE, Read DJ. 2008. Mycorrhizal symbiosis. San Diego, CA, USA: Academic Press.

Stamatakis A. 2006. Raxml-vi-hpc: maximum likelihood-based phylogenetic analyses with thousands of taxa and mixed models. Bioinformatics 22: $2688-2690$.

Strother PK, Al-Hajri S, Traverse A. 1996. New evidence for land plants from the lower middle ordovician of saudia arabia. Geology 24: $55-58$.

Tamura K, Dudley J, Nei M, Kumar S. 2007. Mega4: molecular evolutionary genetics analysis (mega) software version 4.0. Molecular Biology and Evolution 24: 1596-1599.

Thompson JD, Gibson TJ, Plewniak F, Jeanmougin F, Higgins DG. 1997. The clustal_x windows interface: flexible strategies for multiple sequence alignment aided by quality analysis tools. Nucleic Acids Research 25: 4876-4882.

Trappe JM. 1987. Phylogenetic and ecological aspects of mycotrophy in the angiosperms from an evolutionary standpoint. In: Safir GR, ed. 
Ecophysiology of va mycorrhizal plants. Boca Raton, FL, USA: CRC, 5-25.

Trappe JM. 1996. What is a mycorrhiza? Proceedings of the 4th European symposium on mycorrhizae. Granada, Spain: EC Report EUR 16728, 3-9.

Wang B, Qiu Y-L. 2006. Phylogenetic distribution and evolution of mycorrhizas in land plants. Mycorrhiza 16: 299-363.

Wellman CH, Osterloff PL, Mohiuddin U. 2003. Fragments of the earliest land plants. Nature 425: 282-285.

Yang Z. 2000. Phylogenetic analysis by maximum likelihood (paml), version 3.0. London, UK: University College London.

Yano K, Yoshida S, Müller J, Singh S, Banba M, Vickers K, Markmann K, White C, Schuller B, Sato $S$ et al. 2008. Cyclops, a mediator of symbiotic intracellular accommodation. Proceedings of the National Academy of Sciences, USA 105: 20540-20545.

Zhang J, Nielsen R, Yang Z. 2005. Evaluation of an improved branch-site likelihood method for detecting positive selection at the molecular level. Molecular Biology and Evolution 22: 2472-2479.

\section{Supporting Information}

Additional supporting information may be found in the online version of this article.

Fig. S1 A maximum likelihood tree derived from the Doesn't Make Infections 1 (DMII) genes of 33 land plants.

Fig. S2 A maximum likelihood tree derived from the Doesn't Make Infections 3 (DMI3) genes of 40 land plants.
Fig. S3 A maximum likelihood tree derived from the Interacting Protein of DMI3 (IPD3) genes of 20 land plants.

Fig. S4 A maximum likelihood tree obtained from analysis of the combined matrix of three mycorrhizal genes (Doesn't Make Infections 1 (DMII), Doesn't Make Infections 3 (DMI3) and Interacting Protein of DMI3 (IPD3)) of 40 land plants.

Fig. S5 Alignment of conserved functional domains in the three mycorrhizal proteins Doesn't Make Infections 1 (DMI1) (A), Doesn't Make Infections 3 (DMI3) (B), and Interacting Protein of DMI3 (IPD3) (C).

Table S1 Results of mycorrhizal formation on Medicago truncatula Doesn't Make Infections 3 (dmi3) mutant plants transformed with bryophyte orthologs

Table S2 Calcium-dependent protein kinase (CDPK) sequences used in this study

Please note: Wiley-Blackwell are not responsible for the content or functionality of any supporting information supplied by the authors. Any queries (other than missing material) should be directed to the New Phytologist Central Office.

\section{About New Phytologist}

- New Phytologist is owned by a non-profit-making charitable trust dedicated to the promotion of plant science, facilitating projects from symposia to open access for our Tansley reviews. Complete information is available at www.newphytologist.org.

- Regular papers, Letters, Research reviews, Rapid reports and both Modelling/Theory and Methods papers are encouraged. We are committed to rapid processing, from online submission through to publication 'as-ready' via Early View - our average submission to decision time is just 29 days. Online-only colour is free, and essential print colour costs will be met if necessary. We also provide 25 offprints as well as a PDF for each article.

- For online summaries and ToC alerts, go to the website and click on 'Journal online'. You can take out a personal subscription to the journal for a fraction of the institutional price. Rates start at $£ 151$ in Europe/\$279 in the USA \& Canada for the online edition (click on 'Subscribe' at the website).

- If you have any questions, do get in touch with Central Office (newphytol@lancaster.ac.uk; tel +44 1524 594691) or, for a local contact in North America, the US Office (newphytol@ornl.gov; tel +1 865576 5261). 